\title{
CLIMATE CHANGE AND AGRICULTURE PAPER Application of long-range weather forecasts to agricultural decision problems in Europe
}

\author{
P. CALANCA ${ }^{1 *}$, D. BOLIUS ${ }^{1}$, A. P. WEIGEL ${ }^{2}$ AND M. A. LINIGER ${ }^{2}$ \\ ${ }^{1}$ Agroscope Reckenholz-Tänikon, Research Station ART, Air Pollution and Climate Group, Reckenholzstrasse \\ 191, 8032 Zurich, Switzerland \\ ${ }^{2}$ Federal Office of Meteorology and Climatology MeteoSwiss, Krähbühlstrasse 58, 8044 Zürich, Switzerland
}

(Revised MS received 16 March 2010; Accepted 14 June 2010; First published online 5 October 2010)

\begin{abstract}
SUMMARY
Agriculture can benefit substantially from long-range weather forecasts, for the month or the season, which can help to optimize farming operations and deal more effectively with the adverse impacts of climate variability, including extreme weather events. In the context of climate change, long-range weather forecasts also represent key elements for the development of adaptation strategies. In spite of an undeniable potential, long-range forecasts issued for instance by the European Centre for MediumRange Weather Forecasts (ECMWF) have yet to find widespread application in European agriculture. To address partially the question of why this is the case, the performance of the ECMWF monthly ensemble forecasting system was examined. It was noted that predictability is currently limited to about 3 weeks for temperature and 2 weeks for precipitation and solar radiation. This may appear deceptive at first sight, but it was noticed that precipitation forecasts over a month are, overall, at least as valuable as information obtained from observed climatology. Encouraged by this finding, the possibility of using monthly forecasts to predict soil water availability was tested. In an operational context, this could serve as a basis for scheduling irrigation. Positive skills were found for lead times of up to 1 month. It was concluded that more systematic investigations of the possibilities offered by long-range forecasts should be undertaken in the future. However, this will require additional efforts to increase the quality of the forecasts, design appropriate application tools and promote the dissemination of the outcome within the agriculture community.
\end{abstract}

\section{INTRODUCTION}

Thanks to advances in the modelling of coupled ocean-atmosphere dynamics, ensemble predictions of the atmospheric state over a season have become well established and are operationally issued by many weather services. The potential benefits from longrange weather predictions in agricultural decision problems have been pointed out by many authors (e.g. Hansen 2005; Meinke \& Stone 2005; Sivakumar 2006). This holds true, in particular, for regions where the impact of the El Niño/Southern Oscillation (ENSO) on the local or regional climate is

* To whom all correspondence should be addressed. Email: pierluigi.calanca@art.admin.ch pronounced, a condition that has prompted a number of initiatives in developing countries (e.g. Harrison et al. 2007; Patt et al. 2007).

In view of the possible impacts of climate change on agriculture, long-range probabilistic forecasts could also represent a key element of adaptation, above all in relation to what Olesen \& Bindi (2002) call shortadjustments, i.e. autonomous actions that can be implemented without major system changes. Examples of weather-sensitive decision problems of this sort are the choice of crops and crop sequences, adjustments in the cropping calendar, scheduling of irrigation and fertilizer applications, application of pesticides, and so on (Wilks 1997; Meinke \& Stone 2005). In practice, however, the decision process often requires precise weather forecasts. 
In Europe, monthly and seasonal probabilistic weather forecasts are far from being systematically employed for guiding farming operations or helping the decision-making process in extension services. This may be because recent studies provide a somewhat inconclusive picture concerning the utility of the forecasts. On the one hand, investigations conducted in the framework of the DEMETER project (Development of a European Multimodel Ensemble System for Seasonal to Interannual Climate Prediction; Palmer et al. 2004) seem to justify an optimistic attitude, at least in relation to applications at the regional and national scale (Cantelaube \& Terres 2005; Marletto et al. 2005; Marletto et al. 2007). On the other hand, little benefit has been found at the local scale (Semenov \& Doblas-Reyes, 2007).

Since DEMETER, some progress has been made in relation to long-range weather predictions, in particular, with respect to ensemble forecasts over a month. Compared to short- and medium-range forecasts, monthly forecasts represent a significant extension of the prediction horizon and could, therefore, provide a valuable source of information for a variety of decision problems, in particular, operations that do not benefit from longer forecasts (Lawless \& Semenov 2005).

The purpose of the present paper is to highlight the possibilities for applying long-range weather forecasts to agricultural decision problems in Europe. After reviewing the quality of the monthly forecasts issued by the European Centre for Medium-Range Weather Forecasts (ECMWF), the study examines whether bias correction of the precipitation forecasts by statistical methods provide advantages in terms of predictive ability. As an example of an agricultural application, monthly forecasts are considered for predicting soil water availability at the local scale. A more general discussion on the research and technical needs related to the set up of agricultural decision systems based on long-range forecasts concludes the paper.

\section{QUALITY OF ENSEMBLE MONTHLY FORECASTS OVER EUROPE: A REVIEW}

The ECMWF monthly ensemble forecasting system used in the present study has been described in length by Vitart (2004) and the reader should refer to that paper for detailed information. In short, the system consists of a coupled ocean-atmosphere global circulation model. The ocean component is the Hamburg Primitive Equation Model (HOPE; Wolff et al. 1997). It is run at a horizontal resolution of $1 \cdot 4^{\circ}$, corresponding to $c .155 \mathrm{~km}$ outside the tropics. The atmospheric component is the ECMWF atmospheric model integrated forecast system (IFS). It is run at a horizontal resolution of $1125^{\circ}$ corresponding to $c$. $125 \mathrm{~km}$ outside the tropics.
Forecasts for the forthcoming 32 days are issued once a week. They are set up as ensemble forecasts with 51 individual members. Along with each realtime forecast, five-member ensemble re-forecasts with the same starting day of the year and lead-time are generated for the previous 12 years to provide a corresponding climatology. The smaller size of the reforecasts has to be taken into account in evaluations of the prediction skill (Müller et al. 2005; Weigel et al. 2007). The ECMWF issues the monthly forecasts as weekly means, with forecasted fields for weeks 1, 2, 3 and 4 corresponding to averages over days 5-11, $12-18,19-25$ and $26-32$, respectively.

The performance of the ECMWF monthly ensemble forecasting system in relation to near-surface temperature has been systematically examined by Weigel et al. (2008), who found that over Europe the model develops a substantial negative bias (up to $-2 \mathrm{~K}$ ) during week 1 . The bias amplifies as the integration proceeds but the error growth saturates after about 20 days of integration.

Decreasing performance over time is also apparent when considering skill metrics such as the de-biased ranked probability skill score, as defined in Weigel et al. (2008). Over Europe, prediction skill exceeds a value of 0.3 during week 1 , dropping below $0 \cdot 1$ during week 2 . However, even during weeks 3 and 4 prediction skill remains mostly positive, suggesting that the forecasts are only rarely worse than climatology.

As discussed by Rodwell \& Doblas-Reyes (2006), analysis of skill on the basis of the weekly averages penalizes the outcome, because skill does not only vary as a function of lead time but also averaging period. As a rule, prediction skill is better for longer averaging times (up to the lead time); the reason is twofold. First, extending the averaging interval implies that more of the skilful information from earlier stages of the integration contributes to the mean. For instance, the operational forecast to day 18 includes information only from days 12 to 18 ; however if the averages were taken over a 2 -week interval, it would include information from day 5 onwards. Second, high-frequency, unpredictable noise is more effectively filtered out with longer averaging times.

Assessments of the monthly forecasting systems for precipitation have been less systematic than for temperature. There is, however, evidence that the quality of the forecasts is worse than for near-surface temperature. In general, the basic problem of current forecasting systems is their tendency to overestimate the number of rainy days but underestimate rainfall intensity (Ines \& Hansen 2006). Work by Buizza et al. (1999) and Mullen \& Buizza (2001, 2002) suggests that for events characterized by moderate intensity, skilful predictions are possible for up to a week. However, accuracy decreases as the intensity threshold increases and for more intensive events forecasts show little skill, even for very short lead times. 
Table 1. Skill scores of the ECMWF monthly forecasting system in predicting near-surface temperature $(T)$, precipitation $(P)$ and solar radiation $(R)$ over the Swiss Central Plateau. Details of calculation are described in the text. Daily data were averaged over 7, 14, 21 and 28 days for forecasts out to day 11, 18, 25 and 32, respectively.

Skill scores for the summer season are given in brackets

\begin{tabular}{lcccc}
\hline \hline \multirow{2}{*}{ Variable } & \multicolumn{3}{c}{ Lead time } \\
\cline { 2 - 5 }$T$ & 11 days & 18 days & 25 days & 32 days \\
$P$ & $0 \cdot 55(0 \cdot 67)$ & $0 \cdot 39(0 \cdot 43)$ & $0 \cdot 24(0 \cdot 27)$ & $0 \cdot 17(0 \cdot 23)$ \\
$R$ & $0 \cdot 29(0 \cdot 16)$ & $0 \cdot 18(0 \cdot 07)$ & $0 \cdot 07(0 \cdot 03)$ & $0 \cdot 01(-0 \cdot 03)$ \\
\hline \hline
\end{tabular}

Part of the problem is probably caused by the relatively low spatial resolution of the atmospheric component of current forecasting systems. Increasing the spatial resolution could, therefore, help to improve the quality of the forecasts, but only if this is not realized at the cost of a smaller ensemble size. Mullen \& Buizza (2002) argued that low-resolution precipitation forecasts with large ensemble size could ultimately be more valuable to the end-users and decision-makers than high-resolution forecasts with small ensemble size, particularly in relation to heavy precipitation events.

\section{QUALITY OF ENSEMBLE MONTHLY FORECASTS OVER SWITZERLAND}

To better appreciate the forecasting skill of the ECMWF ensemble prediction system at the regional scale, monthly forecasts of near-surface temperature, precipitation and solar radiation for the area of the Swiss Central Plateau were examined. Solar radiation was included in the analysis as it is one of the main drivers of crop growth, but only seldom (if at all) considered in discussions of long-range probabilistic forecasts.

Prediction skill was assessed by comparing the socalled re-forecasts covering the period 1994-2005 to observations valid for the same period. As explained in the previous section, the re-forecasts were produced to provide a climatology for the operational monthly forecasts issued for the year 2006. All fields were interpolated to a $1 \times 1^{\circ}$ grid resolution. The analysis was performed for six representative sites, but only the results for a meteorological station on the Swiss

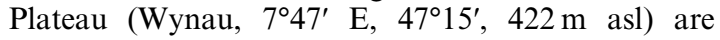
presented in the current paper.

For this location, a substantial negative temperature bias was found (of the order of $-3 \mathrm{~K}$ ), and a positive bias both in relation to the occurrence of wet days (of the order of $+0 \cdot 5$ ) as well as solar radiation (of the order of $+0 \cdot 1$ ). The temperature bias should be considered in relation to the inaccurate representation of the Alpine topography in the forecasting system. It is not considered further because it can be effectively removed based on the altitude bias and the assumption of a standard lapse rate. Removing the precipitation bias is more delicate and will be discussed in the following sections.

Following the suggestions of Müller et al. (2005) and Weigel et al. $(2007,2008)$ the de-biased ranked probability skill score was adopted as a measure of forecast quality. This method is not sensitive to the size of the ensemble, which in the present case varies considerably between forecasts (51 individual members) and re-forecasts (5 members). For all fields, mean values were computed depending on the lead time, taking averages over days 5-11, 5-18, 5-25 and 5-32 for weekly, bi-weekly, 3-weekly and monthly forecasts, respectively.

Results are presented in Table 1 and reveal several interesting features: (i) largely positive skill values up to a month are obtained for all variables, suggesting that monthly probabilistic forecasts are no worse than climatology even in a region characterized by complex topography and substantial biases in the model output; (ii) skill scores for precipitation and solar radiation are significantly lower than for near-surface temperature but still significantly larger than zero up to a lead time of $c .20$ days; (iii) for temperature and solar radiation, but not for precipitation, skill scores calculated only over the 3 summer months (see values in brackets in the table) are better than those computed for the year as a whole, which is somewhat at odds with the findings of Weigel et al. (2008) for the northern extra-tropics.

\section{BIAS CORRECTION OF DAILY PRECIPITATION}

In view of the importance of rainfall for crop production, the question of improving the quality of precipitation forecasts arises naturally in the context 
of agricultural decision problems. A simple multiplicative correction of the rainfall intensity provides unbiased estimates of monthly or seasonal precipitation amounts and is readily implemented in practice. However, it is inappropriate for studies that require information on a daily or weekly time scale.

As an alternative, Ines \& Hansen (2006) examined the possibility of applying a two-step correction directly to the daily output of an ensemble forecasting system. Essentially similar to the procedure proposed by Schmidli et al. (2006), the approach involves (i) discarding rainfall events below a calibrated threshold to match the observed frequency of wet days and (ii) mapping the truncated distribution onto a gamma distribution fitted to the observed intensity distribution. Ines \& Hansen (2006) tested the procedure for a location in semi-arid Kenya, and discussed the implications for the simulation of maize growth. They concluded that while the procedure does effectively remove the bias in both frequency of wet days and rainfall intensity, it fails to account for the autocorrelation structure in the observed time series, with negative consequences for simulated maize yields.

As mentioned, the procedure could still be of practical use in a number of situations. Therefore, its performance was tested in relation to the forecasted precipitation over the Swiss Plateau. Specifically, the study examined whether the procedure has positive impact on skill scores and, if not, why not.

As before use was made of the ECMWF 1994-2005 monthly re-forecasts to evaluate the prediction skill, resorting for illustrative purposes to a skill score based on the mean square error without adjustment for the ensemble size (Murphy 1988, equation (15)). This has the advantage that the skill score can be decomposed in terms reflecting different aspects of the degree of agreement between forecasts and observations (Murphy 1988), namely: (i) the square of the correlation coefficient, i.e. a measure for the strength of the linear relation between forecasts and observations; (ii) a term related to the square of the slope of the regression line between forecast and observations; (iii) a term proportional to the square of the difference between the mean forecast and mean observation, i.e. a non-dimensional measure of the overall bias in the forecasts. Terms (ii) and (iii) have a negative impact on the skill score whenever the slope of the regression line between forecasts and observations significantly depart from 1 and the forecasts are biased.

For the Swiss Plateau, it was found that the correction procedure proposed by Ines \& Hansen (2006) had an overall negative impact on the skill score, with e.g. values for week 1 decreasing from $0 \cdot 3$ using uncorrected data to less than $0 \cdot 2$ using bias-corrected data. Decomposition of the skill score revealed that skill loss was mainly associated with a larger departure of the slope of the regression line between forecasts and observations from the ideal 1:1 line than found with the uncorrected data. In turn, this was prompted by changes in the statistical structure of the time series of daily values. Thus, not only is the procedure unable to recover the observed autocorrelation, as found by Ines \& Hansen (2006), but in some instances it can even lead to a deterioration of the statistical properties of the original forecasts.

Based on these findings, an alternative procedure was chosen for the post-processing of monthly forecasts. The approach is based on creating daily input data for application models with the help of a stochastic weather generator and is described in more detail in the next section.

\section{FORECASTING SOIL WATER AVAILABILITY}

The availability of soil water remains one of the main determinants of crop growth, particularly in rain-fed agriculture. For this reason, the possibility of predicting soil water availability up to a month in advance was studied, as an example, by linking the ECMWF monthly weather forecasts to a simple model of the soil water balance. In short, the model represents the root zone as a simple bucket, and computes changes in soil water storage in response to inputs from precipitation and outputs from evapotranspiration and deep percolation (see e.g. Rodriguez-Iturbe et al. 1999). Computation of the evaporative flux is carried out following Calanca (2007), with potential evapotranspiration estimated using the PriestleyTaylor equation (Priestley \& Taylor 1972) and actual evapotranspiration limited according to soil water content.

Apart from the meteorological drivers, the model requires specification of the soil hydraulic properties. The parameters were calibrated by fitting model simulations to measurements of the soil water content from a field experiment running since 2002 at a location close to the study site (Ammann et al. 2007). Results from the calibration showed that the model reproduces soil water dynamics reasonably well, including key features of the drought that accompanied the summer 2003 heat wave (length of dry spells, cumulated soil water deficit, etc.).

For the reasons detailed in the previous section, the probabilistic monthly forecasts were translated into daily realizations of temperature, precipitation and solar radiation consistent with the monthly forecasts with the help of a weather generator. This approach is common in climate studies (Wilks 2002; Hansen \& Indeje 2004; Feddersen \& Andersen 2005; Lawless \& Semenov 2005). The generator used was the LARSWG stochastic weather generator (Semenov \& Barrow 1997, Semenov et al. 1998).

The generator was first conditioned with 25 years of daily weather observations and subsequently run to generate 3000 years of daily data consistent with the 
(a)

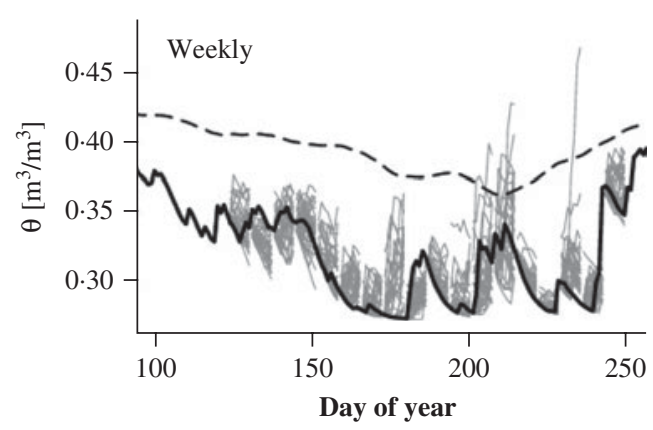

(c)

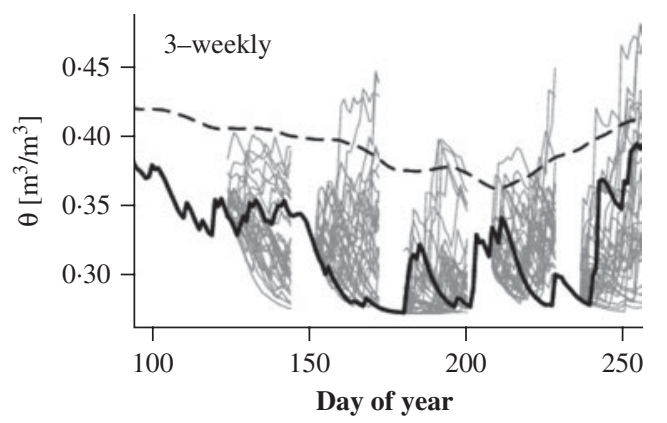

(b)
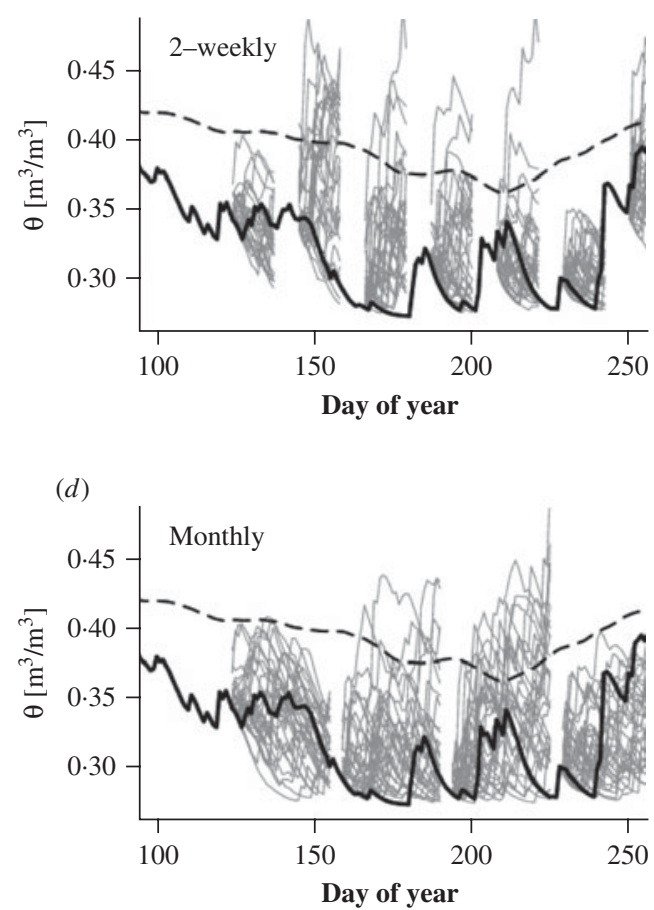

Fig. 1. Illustrative example of the application of a prototype system for forecasting soil volumetric moisture content $(\theta)$ at lead times of $(a) 11,(b) 18,(c) 25$ and $(d) 32$ days. All graphs refer to the spring/summer of 2003, a period characterized by a drought conditions. DOY: day of year. See text for further comments. ( - Individual forecasts. $\longrightarrow$ Reference simulation. -.-- A corresponding 12-year climatology for 1994-2005.

observed climatology. Then, 51 realizations were selected at random from this pool to reproduce the joint probability distributions of temperature, precipitation and solar radiation anomalies for each starting date and lead time indicated by the forecasts. These were then used to drive the soil moisture model over the forecasting period.

To account for the memory effect in soil water dynamics and the sensitivity of forecasted soil water to initial conditions, simulations were initialized by running the model from the beginning of each year up to each starting date using observed weather data (or by setting the initial soil water content to field capacity for the first forecasting period of the year).

An example of ensemble simulations obtained in this manner is shown in Fig. 1. Each panel refers to a different lead time, and predicted soil moisture evolution for each of the individual ensemble members is plotted on the background of a reference simulation driven with observed weather data and a 12-year climatology obtained from simulations for 1994-2005. The example refers to the year 2003, which was characterized by exceptionally high temperatures (Schär et al. 2004), considerable water deficits over extended periods of time (Calanca 2007), and therefore a marked departure from the climatology.

Figure 1 illustrates two key features of the application. First, the dispersion of the ensemble (the spread of the forecast plume) is already considerable for a lead time of 2 weeks, and in some cases even for a lead time of 1 week. Second, even for lead times of 3 weeks, individual members tend to cluster around the reference rather than the climatology. However, systematic departures from the reference can be seen on occasions, suggesting that the forecasts do not always capture the observed evolution, not even in a probabilistic sense.

A similar analysis for all years between 1994 and 2005 confirms the existence of significant predictive skill (larger than or of the order of $0 \cdot 2$ ) for lead times of up to 1 month (Table 2). Compared to precipitation, this represents at least a 2-week extension of the predictability limit. However, owing to a weaker performance of the ECMWF forecasting system in relation to summer precipitation, skill scores for the summer seasons are slightly smaller than for the year as a whole. Moreover, Fig. 1 suggests that this particular application benefits to a large extent from 
Table 2. Skill scores of the prototype forecasting system for predicting soil moisture content $(\theta)$ described in the text. Details are given in the text. Skill scores for the summer season are given in brackets

\begin{tabular}{lcccc}
\hline \hline & \multicolumn{4}{c}{ Lead time } \\
\cline { 2 - 5 } Variable & 11 days & 18 days & 25 days & 32 days \\
\hline$\theta$ & $0.43(0.37)$ & $0.32(0.24)$ & $0.27(0.19)$ & $0.17(0.12)$ \\
\hline \hline
\end{tabular}

the initialization procedure. It therefore appears that applications possessing some degree of inertia may partially overcome intrinsic weaknesses of longrange weather forecasts. In a practical context, this property could help with identifying the other types of applications.

\section{DISCUSSION}

In view of the persistent improvements in the field of weather forecasting, there is a real possibility that agriculture, as with other weather-sensitive human activities, could take advantage of the information provided by long-range forecasts. Efforts to deliver better forecasts have been undertaken along different lines of research, e.g. developments in physical parameterization schemes and multi-model ensemble forecasting (Palmer et al. 2004) and also the recalibration of single-model ensemble predictions (Weigel et al. 2009).

In spite of a promising background, with respect to European agriculture systematic efforts to foster the use of such forecasts still need to be undertaken. To some extent, this is understandable against the background of a limited skill of long-range forecasts, firstly in relation to precipitation. But limited predictability is also of concern in relation to other variables of interest in agrometeorology, such as solar radiation or air humidity. Little has been done to date with respect to these to systematically evaluate the performance of forecasting systems. Promoting targeted research in this direction could help to increase confidence in the forecasts.

In the present study, the quality of monthly precipitation forecasts were examined more closely using the example of the monthly ensemble forecasts issued by the ECMWF for Switzerland. It was found that extending the averaging time beyond the weekly scale at which the forecasts are issued could provide useful forecasts up to about 15 days. This is a sensitive time scale for decision problems involving, e.g. irrigation. Correction of the daily precipitation output, as suggested by Ines \& Hansen (2006), did not improve the prediction skill, since the procedure tends to destroy the auto-correlation structure and reduce skill scores.

Therefore, there is some evidence that processing the output of ensemble forecasting systems via statistical downscaling and/or stochastic weather generation remains, for the time being, the method of choice for retrieving information at the temporal and spatial scales required by application models (Wilks 2002). There have been considerable developments along these lines in recent years (see e.g. Feddersen \& Andersen 2005), including, in particular, the generation of spatially coherent data (see e.g. Wilks 1998, 1999; Semenov \& Brooks 1999). However, further research is needed to develop the downscaling of variables other than near-surface temperature and precipitation (Huth 2005). Additional efforts are also necessary to improve the downscaling of extreme events (Semenov 2008), regardless of progress achieved in the recent past (e.g. Busuioc et al. 2008; Hundecha \& Bárdossy 2008).

From a practical point of view, a case study was presented where decisions based on monthly forecasts proved to have some benefits in predicting soil moisture availability up to a month ahead. Linking monthly forecasts with even a simple soil moisture model could thus serve as a starting point for developing a prediction system aimed at guiding irrigation. In presenting the results it was noted that in this case the decision process benefits from memory effects inherent to the system under consideration (the soil water store). It is not guaranteed that the same conclusion would have been reached, had the target of the investigation been another.

This shows the importance of evaluating the setup of a decision support system relying on longrange forecasts on a case to case basis. Questions that need to be addressed are, among others, whether the forecasts are in an appropriate form, predict the proper variables and refer to the relevant time scales (Wilks 1997; Garbrecht et al. 2005). With regard to the last of these questions, Lawless \& Semenov (2005) have shown that the lead time in prediction of crop yield does not only vary between locations but also depends on the crop characteristics affecting the decision process at a single location. In addition, sufficient care should be taken to fully exploit the probabilistic format of long-range forecasts (DoblasReyes et al. 2007).

Examining the performance of decision support systems in the specific context of their application is also of paramount importance (Hansen et al. 2006). Showing that forecasting systems provide a more reliable decision basis than approaches relying on experience and knowledge of climatology and/or persistence is one of the prerequisites for endorsing a positive attitude toward long-range forecasts by the 
end-users (McCrea et al. 2005). Opening the access to the forecasts, ensuring a better link between the climate and agricultural communities and fostering capacity-building activities are other measures that could help to promote the use of long-range forecasts (Garbrecht et al. 2005). In particular, it is fundamental that end-users and decision-makers appreciate the difference between deterministic short- to medium-range weather forecasts and probabilistic monthly and seasonal forecasts.

Progress in long-range weather forecasting is important in the context of climate change as well, as timely information is needed for risk management and to devise effective measures of adaptation. The impacts of events such as the European heat wave in summer 2003, with uninsured losses for the agricultural sector estimated at US\$12.4 billion (SwissRe 2004), can be dramatic. Climate scenarios suggest that in many parts of Europe events of this sort could occur more often in the future (Beniston 2004). Increasing the preparedness of farmers and other endusers is therefore essential to reduce the economic impacts of climate variability and limit the consequences of extreme events. It is encouraging to see that recent developments at ECMWF have already helped significantly improving the predictability of extreme European summer temperatures (Weisheimer et al. 2009).

Part of this work has grown from activities of the lead author for the Commission on Agricultural Meteorology by the World Meteorological Organization (WMO) and is a contribution to COST Action 734 (Impact of Climate Change and Variability on European Agriculture, http://www. cost734.eu). The case study was supported by the Swiss National Science Foundation through the National Centre for Competence in Research on Climate (NCCR Climate). We thank Mikhail Semenov (Rothamsted Research, Centre for Mathematical and Computational Biology, Harpenden, Herts, AL5 2JQ, U.K.) for making available LARSWG and also to two anonymous reviewers for useful comments.

\section{REFERENCES}

Ammann, C., Flechard, C. R., Leifeld, J., Neftel, A. \& FuHrer, J. (2007). The carbon budget of newly established temperate grassland depends on management intensity. Agriculture, Ecosystems and Environment 121, 5-20.

Beniston, M. (2004). The 2003 heat wave in Europe: a shape of things to come? Geophysical Research Letters 31, L02202. doi: 10.1029/2003GL018857.

Busuioc, A., Tomozeiu, R. \& Cacciamani, C. (2008). Statistical downscaling model based on canonical correlation analysis for winter extreme precipitation events in the Emilia-Romagna region. International Journal of Climatology 28, 449-464.

Buizza, R., Hollingsworth, A., Lalaurette, F. \& Ghelli, A. (1999). Probabilistic predictions of precipitation using the ECMWF Ensemble Prediction System. Weather and Forecasting 14, 168-189.

Calanca, P. (2007). Climate change and drought occurrence in the Alpine region: how severe are becoming the extremes? Global and Planetary Change 57, 151-160.

Cantelaube, P. \& Terres, J.-M. (2005). Seasonal weather forecasts for crop yield modelling in Europe. Tellus 57A, 476-487.

Doblas-Reyes, F. J., Hagedorn, R. \& Palmer, T. N. (2007). Developments in dynamical seasonal forecasting relevant to agricultural management. Climate Research 33, 19-26.

Feddersen, H. \& Andersen, U. (2005). A method for statistical downscaling of seasonal ensemble predictions. Tellus 57A, 398-408.

Garbrecht, J., Meinke, H., Sivakumar, M. V. K., Motha, R. P. \& Salinger, M. J. (2005). Seasonal climate forecasts and adoption by agriculture. EOS Transactions of the American Geophysical Union 86, 227. doi: 10.1029/ 2005 EO240005.

HANSEN, J. W. (2005). Integrating seasonal climate prediction and agricultural models for insights into agricultural practice. Philosophical Transactions of the Royal Society B 360, 2037-2047.

Hansen, J. W. \& IndeJe, M. (2004). Linking dynamic seasonal climate forecasts with crop simulation for maize yield prediction in semi-arid Kenya. Agricultural and Forest Meteorology 125, 143-157.

Hansen, J. W., Challinor, A., Ines, A., Wheeler, T. \& Moron, V. (2006). Translating climate forecasts into agricultural terms: advances and challenges. Climate Research 33, 27-31.

Harrison, M., Kanga, A., Magrin, G. O., Hugo, G., Tarakidzwa, I., Mullen, C. \& Meinke, H. (2007). Use of Seasonal Forecasts and Climate Prediction in Operational Agriculture. CAgM Report No. 102, WMO/ TD No. 1344. Geneva, Switzerland: World Meteorological Organization, Commission for Agricultural Meteorology.

Hundecha, Y. \& BÁrdossy, A. (2008). Statistical downscaling of extremes of daily precipitation and temperature and construction of their future scenarios. International Journal of Climatology 28, 589-610.

Huth, R. (2005). Downscaling of humidity variables: a search for suitable predictors and predictands. International Journal of Climatology 25, 243-250.

Ines, A. V. M. \& Hansen, J. W. (2006). Bias correction of daily GCM rainfall for crop simulation studies. Agricultural and Forest Meteorology 138, 44-53.

Lawless, C. \& Semenov, M. A. (2005). Assessing leadtime for predicting wheat growth using a crop simulation model. Agricultural and Forest Meteorology 135, 302-313.

Marletto, V., Zinoni, F., Criscuolo, L., Fontana, G., Marchesi, S., Morgillo, A., Van Soetendael, M., Ceotto, E. \& Andersen, U. (2005). Evaluation of downscaled DEMETER multi-model ensemble seasonal hindcasts in a northern Italy location by means of a model 
of wheat growth and soil water balance. Tellus $\mathbf{5 7 A}$, 488497.

Marletto, V., Ventura, F., Fontana, G. \& Tomei, F. (2007). Wheat growth simulation and yield prediction with seasonal forecasts and a numerical model. Agricultural and Forest Meteorology 147, 71-79.

McCrea, R., Dalgleish, L. \& Coventry, W. (2005). Encouraging use of seasonal climate forecasts by farmers. International Journal of Climatology 25, 1127-1137.

Meinke, H. \& Stone, R. C. (2005). Seasonal and interannual climate forecasting: the new tool for increasing preparedness to climate variability and change in agricultural planning and operations. Climatic Change 70, 221-253.

Mullen, S. L. \& Buizza, R. (2001). Quantitative precipitation forecasts over the United States by the ECMWF Ensemble Prediction System. Monthly Weather Review 129, 638-663.

Mullen, S. L. \& Buizza, R. (2002). The impact of horizontal resolution and ensemble size on probabilistic forecasts of precipitation by the ECMWF Ensemble Prediction System. Weather and Forecasting 17, 173-191.

Müller, W. A., Appenzeller, C., Doblas-Reyes, F. J. \& LINIGER, M. A. (2005). A debiased ranked probability skill score to evaluate probabilistic ensemble forecasts with small ensemble sizes. Journal of Climate 18, 15131523.

Murphy, A. H. (1988). Skill scores based on the mean square error and their relationships to the correlation coefficient. Monthly Weather Review 116, 2417-2424.

Olesen, J. E. \& Bindi, M. (2002). Consequences of climate change for European agricultural productivity, land use and policy. European Journal of Agronomy 16, 239-262.

Palmer, T. N., Alessandri, A., Andersen, U., Cantelaube, P., Davey, M., Délécluse, P., Déqué, M., Díez, E., Doblas-Reyes, F. J., Feddersen, H., Graham, R., Gualdi, S., Guérémy, J.-F., Hagedorn, R., Hoshen, M., Keenlyside, N., Latif, M., Lazar, A., Maisonnave, E., Marletto, V., Morse, A. P., Orfila, B., Rogel, P., Terres, J.-M. \& Thomson, M. C. (2004). Development of a European multi-model ensemble system for seasonal to inter-annual prediction. Bulletin of the American Meteorological Society 85, 853872.

Patt, A. G., Ogallo, L. \& Hellmuth, M. (2007). Learning from 10 years of climate out look forums in Africa. Science 318, 49-50.

Priestley, C. H. B. \& Taylor, R. J. (1972). On the assessment of surface heat flux and evaporation using large-scale parameters. Monthly Weather Review 100, 81-92.

Rodwell, M. J. \& Doblas-Reyes, F. J. (2006). Mediumrange, monthly, and seasonal prediction for Europe and the use of forecast information. Journal of Climate 19, 6025-6046.

Rodriguez-Iturbe, I., Porporato, A., Ridolfi, L., IsHaM, V. \& Cox, D. R. (1999). Probabilistic modelling of water balance at a point: the role of climate, soil and vegetation. Proceedings of the Royal Society of London A 455, 3789-3805.

Schär, C., Vidale, P. L., Lüthi, D., Frei, C., Häberli, C., Liniger, M. A. \& Appenzeller, C. (2004). The role of increasing temperature variability in European summer heatwaves. Nature 427, 332-336.
Schmidli, J., Frei, C. \& Vidale, P.-L. (2006). Downscaling from GCM precipitation: a benchmark for dynamical and statistical downscaling methods. International Journal of Climatology 26, 679-689.

Semenov, M. A. (2008). Simulation of weather extreme events by a stochastic weather generator. Climate Research 35, 203-212.

Semenov, M. A. \& Barrow, E. M. (1997). Use of a stochastic weather generator in the development of climate change scenarios. Climatic Change 35, 397-414.

Semenov, M. A. \& Brooks, R. J. (1999). Spatial interpolation of the LARS-WG stochastic weather generator in Great Britain. Climate Research 11, 137-148.

Semenov, M. A. \& Doblas-Reyes, F. J. (2007). Utility of dynamical seasonal forecasts in predicting crop yield. Climate Research 34, 71-81.

Semenov, M. A., Brooks, R. J., Barrow, E. M. \& Richardson, C. W. (1998). Comparison of the WGEN and LARS-WG stochastic weather generators in diverse climates. Climate Research 10, 95-107.

Sivakumar, M. V. K. (2006). Climate prediction and agriculture: current status and future challenges. Climate Research 33, 3-17.

Swiss Reinsurance Company (SwissRe) (2004). Natural Catastrophes and Man-made Disasters in 2003: Many Fatalities, Comparatively Moderate Insured Losses. Sigma Publication Series 1. Zurich, Switzerland: Swiss Reinsurance Company. Available online at http://www. swissre.com (verified 29 July 2010).

Vitart, F. (2004). Monthly forecasting at ECMWF. Monthly Weather Review 132, 2761-2779.

Weigel, A. P., Liniger, M. A. \& Appenzeller, C. (2007). The discrete Brier and ranked probability skill scores. Monthly Weather Review 135, 118-124.

Weigel, A. P., Baggenstos, D., Liniger, M. A., Vitart, F. \& Appenzeller, C. (2008). Probabilistic verification of monthly temperature forecasts. Monthly Weather Review 136, 5162-5182.

Weigel, A. P., Liniger, M. A. \& Appenzeller, C. (2009). Seasonal ensemble forecasts: are recalibrated single models better than multimodels? Monthly Weather Review 137, 1460-1479.

Weisheimer, A., Doblas-Reyes, F. J. \& Palmer, T. N. (2009). Predictability of the extreme summer 2003 over Europe. Geophysical Research Abstracts 11, EGU20094862.

WILKs, D. S. (1997). Forecast value: prescriptive decision studies. In Economic Value of Weather and Climate Forecasts (Eds R. W. Katz \& A. H. Murphy), pp. 109145. Cambridge, UK: Cambridge University Press.

WILKS, D.S. (1998). Multisite generalization of a daily stochastic precipitation generation model. Journal of Hydrology 210, 178-191.

WILKS, D. S. (1999). Simultaneous stochastic simulation of daily precipitation, temperature and solar radiation at multiple sites in complex terrain. Agricultural and Forest Meteorology 96, 85-101.

WiLKs, D.S. (2002). Realizations of daily weather in forecast seasonal climate. Journal of Hydrometeorology 3, 195-207.

Wolff, J. O., Maier-Raimer, E. \& Legutke, S. (1997). The Hamburg Ocean Primitive Equation Model. Technical Report 13. Hamburg, Germany: Deutsches Klimarechenzentrum. 